\title{
Characterization of Village Chicken Production and Marketing Systems in Chiro District, West Hararghe Zone, Oromia Regional State, Ethiopia
}

\author{
Tarekegn Demeke \\ Department of Animal Science, Collage of Agriculture, Oda Bultum University, Chiro, Ethiopia
}

Email address:

tarekedeme@gmail.com

\section{To cite this article:}

Tarekegn Demeke. Characterization of Village Chicken Production and Marketing Systems in Chiro Town, West Hararghe Zone, Oromia Regional State, Ethiopia. Advances in Bioscience and Bioengineering. Vol. 8, No. 3, 2020, pp. 56-62. doi: 10.11648/j.abb.20200803.13

Received: January 8, 2020; Accepted: August 3, 2020; Published: August 19, 2020

\begin{abstract}
The study was conducted to generate comprehensive information on village chicken production, management and marketing systems in Chiro district of West Harerghe Zone, Oromia Regional State, Ethiopia. Majority of the respondents in the study area were female $(66.7 \%)$. The largest proportions of household heads in the study area $(70 \%)$ were illiterate. the overall household income in the study area was generated from agriculture (76.7\%). Among agricultural activities, livestock production was contributed $53.3 \%$ for the household income. The entire households in the study area were kept exotic chicken ecotype. The major sources of that chicken were gift from governments $(60 \%)$. Most of the household in the study area was practiced backyard chicken production systems $(73.3 \%)$. The major objective of raising chicken in the study area was egg production $(80 \%)$ and Meat production $(10 \%)$. The majority of the households in the study area were practiced semi-extensive management systems $(60 \%)$. The entire households in the study area were providing supplementary feed and water for their chicken. The main reason for providing supplementary feed was to increase egg yield $(70 \%)$ followed by shorting of broodiness $(23.3 \%)$. the entire households in the study area were hatching the egg by using natural incubation hence broody hens used as a natural incubation. Most of the households in the study area were sold their chicken through formal market $(63.3 \%)$ for the consumers $(83.3 \%)$. The major constraints of chicken marketing in the study area were instable chicken price, poor sales/demand seasonality, poor infrastructure, lack of credit/financial support and lack of market place. This finding was put baseline for understanding about production, management and marketing practices of village chicken and serve as a base for designing a sustainable chicken production and management strategies in the study area.
\end{abstract}

Keywords: Management, Marketing Systems, Village Chicken, Chiro Town

\section{Introduction}

In Ethiopia chickens are the most widespread where almost every rural family owns chickens, which contribute greatly to supply of eggs and meat [1]. Rural chicken in Ethiopia represents a significant part of the national economy in general and the rural economy in particular and contribute to $98.5 \%$ and $99.2 \%$ of the national egg and chicken meat production, respectively $[2,3]$. Poultry production system in Ethiopia is indigenous and an integral part of farming system and predominantly prevailing in the country and it is characterized by small flock, minimal input and unorganized marketing system [4]. About 59.49 million chicken heads with about $90.9 \%, 4.7 \%$ and $4.4 \%$ of chicken population are indigenous, hybrid and exotic breeds are found in Ethiopia [5]. Out of these heads, about 33.5\% are found in Amhara region. Generally, in order for decision-makers to address poultry related challenges in production and marketing and to improve the nutrition, food security and livelihood of rural households by enhancing the benefits from poultry through appropriate production and marketing extension, it is essential to generate appropriate technologies which are socially acceptable, environmentally sound and economically feasible. The main advantages of chicken marketing research are defining the needs and nature of customers and their ability and desire to buy, scanning the business environment, gathering needed information for decision-making, reducing risk, helping in production planning and monitoring and 
controlling marketing activities [6]. Access to markets affects the price and transaction costs and is influenced by access to infrastructure and information [7]. Although there are some studies conducted on characterization of chicken production systems in some locations in Ethiopia, they are not comprehensive enough and did not relate production and productivity with marketing. Some of these studies were also site specific. Characterization of the prevailing chicken production and marketing system is therefore an essential prerequisite to bring this into effect. Therefore, this paper synthesizes studies on indigenous chicken production, productive performance and marketing systems from Chiro town, West Hararghe Zone, Oromia Regional State Ethiopia.

\section{Materials and Methods}

\section{Description of the Study Area}

Chiro District is located in West Harerghe Zone, Oromia Regional State, Ethiopia. Its altitude ranges from 1500 to 3060 meters above sea level. Chiro district is $326 \mathrm{~km}$ far from Addis Ababa and bordered on the East by Tullo district, on the North by Meiso district, on the South by Gemechis and on the west by Guba koricha. The total human population of the town is 207553 of which 106277 are males and females 101276. The average temperature of the town is $27.5^{\circ} \mathrm{c} 38.5^{\circ} \mathrm{c}$. It has three Agro ecology (54\% lowland, 38\% mid altitude, $8 \%$ highland).

Data Collection Methods

Both primary and secondary sources of data were used for the study. To collect the primary data, a semi-structured questionnaire was designed. The questionnaire was pre-tested before administration and some re-arrangement, reframing and correcting in accordance with respondent perception was done. The questionnaire was administered to the selected households or representatives by a team of researchers. Group discussion was also conducted with extension workers, model farmers and Developmental Agents (DAs) since it is believed that such individuals have better information about the overall production potential of the chicken as well as the production system, husbandry practice and marketing systems The secondary data was collected from the study district office of livestock and fishery resources to complement the production system and agro ecology along with climate, vegetation cover, topography, human population and livestock population.

Sampling techniques and sample size

The sampling method employed for this study was purposive sampling technique, which was based on the potential of chicken population/production. Accordingly three sampling sites or rural 'kebeles' (lowest local administration unit in Ethiopia) were selected in the study town, based on chicken flock size per household, suitability of the area for chicken production and accessibility. By considering the time, cost and resource limitation from each rural kebeles, 10 household heads having indigenous chicken ecotype were randomly selected for interview. Generally, 30 households were selected from the three sampling sites (rural kebeles) for interview.

\section{Data Management and Statistical Data Analysis}

The data collected from each study site was checked for any error and corrected during the study period, coded and entered into computer for further analysis.

Questionnaire data: Data collected through questionnaire was described by descriptive statistics using Statistical Package for Social Sciences [8]. Chi-square was employed when required to test the independence of categorical variables and to assess association between levels of categorical variables. Ranked data were evaluated based on calculated indices. An index was calculated to provide overall ranking for qualitative data such as constraints of chicken production, and common chicken diseases in the study area according to the following formula: Index $=\Sigma$ of [3 for rank $1+2$ for rank $2+1$ for rank 3] given for particular qualitative variables divided by $\Sigma$ of [ 3 for rank $1+$ 2 for rank $2+1$ for rank 3] for all qualitative variables considered.

\section{Results and Discussion}

\section{General Household Characteristics in the Study Area}

The household sex, marital statuses, age and educational background of households in the study area are summarized in Table 1 . The majority of the respondents in the study area were female $(66.7 \%)$. The proportion of male respondents was clearly low (33.3\%). This might be due to work load that men experience in field and socio-cultural background while females are primary sources that get interviewed in such surveys. According to respondents, in this study the proportions of married, unmarried (single), divorced and widow households were $70 \%, 23.3 \%, 1.3 \%$ and $1.3 \%$, respectively. The age of most household heads in the study district were ranged from 30-39 years (50\%). The largest proportions of household heads in the study area $(70 \%)$ were illiterate. Low education level might have effect in implementing intensive chicken production like keeping records, distribution of exotic chicken ecotype and implement improved management practices. Thus teaching them would be beneficial to use their indigenous knowledge in scientific way and easily adopting improved technologies like hatching by incubator, selection of high productive chicken and feeding well ration feed. Similar to the current results, in Meket district majority of the respondents participated in chicken production were Female and most of them are illiterate [11].

Table 1. Sex, age, marital status and education background of respondents in the study area.

\begin{tabular}{lll}
\hline Description of demography & & \\
\hline Demography of households & $\mathbf{N}$ & $\mathbf{\%}$ \\
\hline Sex & & \\
Male & 10 & 33.3 \\
Female & 20 & 66.7 \\
Total & 30 & 100.0 \\
Age & & \\
$<20$ & - & - \\
\hline
\end{tabular}




\begin{tabular}{lll}
\hline Description of demography & & \\
\hline Demography of households & $\mathbf{N}$ & $\mathbf{\%}$ \\
\hline $20-29$ & 9 & 30 \\
$30-39$ & 15 & 50 \\
$40-49$ & 5 & 16.7 \\
$50-59$ & - & - \\
$>60$ & 1 & 3.3 \\
Total & 30 & 100.0 \\
Marital status & & \\
Married & 21 & 70 \\
Single & 7 & 23.3 \\
Divorced & 1 & 1.3 \\
Widow & 1 & 1.3 \\
Total & 30 & 100.0 \\
Education background & & \\
Illiterate & 21 & 70.0 \\
Primary school (1-4) & 5 & 16.7 \\
Elementary school (5-8) & 1 & 3.3 \\
Secondary school (9-10) & 2 & 6.7 \\
Preparatory school 11-12) & 1 & 3.3 \\
Total & 30 & 100.0 \\
\hline
\end{tabular}

$\mathrm{N}=$ number of households, $\%=$ percent

\section{Socio Economic Condition of Farming Community}

As summarized in Table 2, the overall household income in the study area was generated from both agriculture and marchant $(76.7 \%)$, daily labor $(3.3 \%)$ and agriculture and agriculture only (20\%). Among agricultural activities, livestock production was contributed $20.6 \%$ for the household income. Crop production also contributed 51.6\% and both crop and livestock production was contributed $26.7 \%$. Among livestock activity poultry production was the main one $(50 \%)$.

Table 2. Socio economic condition of farming community in the study area.

\begin{tabular}{lll}
\hline Description & & \\
\hline Socio economic condition & N & \% \\
\hline Main household income & & \\
Agriculture & 6 & 20 \\
Daily labor & 1 & 3.3 \\
Merchant & - & - \\
Agriculture and Merchant & 23 & 76.7 \\
Total & 30 & 100.0 \\
Main household farming activity & & \\
Crop production & 15 & 51.6 \\
Livestock production & 6 & 20.6 \\
Both & 8 & 26.7 \\
Total & 29 & 100.0 \\
Major Livestock production & & \\
Sheep production & - & - \\
Cattle production & 2 & 14.3 \\
Poultry production & 7 & 50.0 \\
Goat production & 5 & 35.7 \\
Total & 14 & 100.0 \\
\hline
\end{tabular}

Chicken Production Systems

As illustrated in Table 3, the entire households in the study area were kept exotic chicken ecotype. The major sources of that chicken were gift from governments $(60 \%)$, purchased from unknown sources (33.3\%) and gift from Nongovernmental organizations (NGOs) $(6.7 \%)$. In contrast to the current result, the major source of exotic chicken $((60 \%)$ in Meket district were purchased from unknown sources [9].
Based on the information obtained from the respondents, the objective of raising chicken in the study area was egg production $(80 \%)$, income generation $(6.7 \%)$, meat production (10\%) and for religious ceremony (3.3\%). In line with the current result, village households in tropics like Ethiopia keep their chicken for purposes other than for reproduction, sale and consumptions, in particular for their socio-religious functions at home, gifts, for ceremonies and chicken are given as or received to show or to accept a good relationship or to say thanks for favor or help [10]. According to the information obtained during the survey, the main sources of local roosters in chiro town was hatched at the house/flock $(63.3 \%)$ followed by purchased from unknown sources $(30 \%)$. According to the information obtained from the respondents, most of the household in the study area was practiced backyard chicken production systems $(73.3 \%)$. Such production systems may result in slow growing, and poor layers of small sized eggs. Village chickens however are ideal mothers, good sitters, hatch their own eggs, excellent foragers and have immunities to resist common poultry diseases.

Table 3. Chicken Production systems in Chiro district.

\begin{tabular}{|c|c|c|}
\hline \multicolumn{3}{|l|}{ Description } \\
\hline Chicken Production systems & $\mathbf{N}$ & $\%$ \\
\hline \multicolumn{3}{|l|}{ Do you have exotic chicken } \\
\hline Yes & 30 & 100.0 \\
\hline No & - & - \\
\hline \multicolumn{3}{|l|}{ Sources of exotic chicken } \\
\hline Purchased from unknown sources & 10 & 33.3 \\
\hline Gift from NGOs & 2 & 6.7 \\
\hline Gift from governments & 18 & 60 \\
\hline Total & 30 & 100.0 \\
\hline \multicolumn{3}{|l|}{ Purpose of keeping roosters } \\
\hline For meat production & 6 & 20.0 \\
\hline For sale & 1 & 3.3 \\
\hline For breeding purpose & 23 & 76.7 \\
\hline Total & 30 & 100.0 \\
\hline \multicolumn{3}{|l|}{ Sources of local roosters } \\
\hline Purchased from unknown sources & 9 & 30 \\
\hline Hatched at the flock/home & 19 & 63.3 \\
\hline Gift from NGOs & - & - \\
\hline Gift from governments & 2 & 6.7 \\
\hline Total & 30 & 100.0 \\
\hline \multicolumn{3}{|l|}{ Major objectives of raising chicken } \\
\hline Home consumption & 2 & 6.7 \\
\hline Meat production & 3 & 10.0 \\
\hline Egg production & 24 & 80.0 \\
\hline Egg hatching & - & - \\
\hline For religious ceremony & 1 & 3.3 \\
\hline Total & 30 & 100.0 \\
\hline \multicolumn{3}{|l|}{ Chicken production systems } \\
\hline Backyard chicken production & 22 & 73.3 \\
\hline Small scale chicken production & 8 & 26.7 \\
\hline Large scale chicken production & - & - \\
\hline Total & 30 & 100.0 \\
\hline
\end{tabular}

Flock Structure and Ownership Pattern of chicken

The proportion of different class of animals reflects the management decision of the producers which in turn is determined by their production objective [11]. As summarized in Table 4, the average number local and exotic 
chicken per household (Mean $\pm \mathrm{SE}$ ) in the current study area was $10.09 \pm 1.1$ and $17.42 \pm 1.05$, respectively. In this study, as compared to the other age groups layers made a major share ( $4.93 \pm 0.3$ for local and $8.06 \pm 0.4$ for exotic) in study town followed by pullets $(2.03 \pm 0.2$ for local and $5.72 \pm 0.6$ for exotic).

Table 4. Flock structure of chicken in chiro district.

\begin{tabular}{lllll}
\hline \multirow{2}{*}{$\begin{array}{l}\text { Flock composition of } \\
\text { chicken }\end{array}$} & \multicolumn{3}{l}{ Chicken Ecotype } \\
\cline { 2 - 5 } & \multicolumn{2}{l}{ Local Chicken } & \multicolumn{2}{l}{ Exotic chicken } \\
\cline { 2 - 5 } & Mean \pm SE & Range & Mean \pm SE & Range \\
\hline Young chicks & $1.83 \pm 0.10$ & $0-15$ & $3.21 \pm 0.03$ & $0-15$ \\
Cockerels & $0.67 \pm 0.07$ & $0-3$ & - & - \\
Pullets & $2.03 \pm 0.20$ & $0-40$ & $5.72 \pm 0.6$ & $2-25$ \\
Number of layers & $4.93 \pm 0.3$ & $1-50$ & $8.06 \pm 0.4$ & $2-30$ \\
Number of Cocks & $0.63 \pm 0.1$ & $0-5$ & $0.43 \pm 0.02$ & $0-2$ \\
$\begin{array}{l}\text { Total number of chicken } \\
\text { per household }\end{array}$ & $10.09 \pm 1.1$ & $1-50$ & $17.42 \pm 1.05$ & $2-30$ \\
\hline
\end{tabular}

\section{Chicken management systems}

As summarized in Table 5, the majority of the households in the study area were practiced semi-extensive management systems $(60 \%)$. Based on the information collected from the respondents most of the households in the study area were have a separate chicken house $(86.7 \%)$. In contrast with the current result, the majority of rural community $(69.2 \%)$ in Meket district were practice extensive chicken management [9]. According to the information obtained during the survey, the popular types of housing system in the study area were semi-extensive or restricted range (63.3\%). Most of the household in the study area was cleaned their chicken house $3.3 \pm 0.1$ times a week.

Table 5. Chicken management systems in the study area.

\begin{tabular}{lll}
\hline Description & N & \% \\
\hline Chicken management systems & & \\
\hline Types of management & 11 & 36.7 \\
Extensive & 18 & 60.0 \\
Semi-intensive & 1 & 3.3 \\
Intensive & 30 & 100.0 \\
Total & & \\
Do you have separate chicken house & 26 & 86.7 \\
Yes & 4 & 13.3 \\
No & & \\
Types of housing systems & 10 & 33.3 \\
Extensive/free range & 19 & 63.3 \\
Semi -intensive/restricted range & 1 & 3.3 \\
Intensive/deep litter/cage & 30 & 100.0 \\
Total & & \\
Do you practiced cleaning of chicken house & 29 & 96.7 \\
Yes & 1 & 3.3 \\
No & Mean \pm SE & \\
How many times do you clean per week & \pm 0.1 & \\
\hline
\end{tabular}

Feed resources feeding stratagem and watering

Based on the information obtained from the respondents, the entire households in the study area were providing supplementary feed and water for their chicken (Table 6). As summarized in Table 6 , the main reason for providing supplementary feed was to increase egg yield $(70 \%)$ followed by shorting of broodiness $(23.3 \%)$. Similar to the current finding, [12] reported that, as chicken requires more feed and results in loss of broodiness. Based on the information obtained from the respondents, the most widely used ingredients as a supplementary feed was Maize (70\%) followed by Sorghum (13.3\%). As illustrated in Table 6, most of the households were provide supplementation three times per day (66.7\%) and water $(73.3 \%)$. According to the information obtained during the survey, majority of the households were feed their chicken by using feeding through (70\%). The current finding was similar to the report of [13] who reported that, feeds and feeding systems were potentials for intervention since the majority of the farmers practiced supplementary feeding with locally produced feeds.

Table 6. Feeding and watering practice in the study area.

\begin{tabular}{|c|c|c|}
\hline \multicolumn{3}{|l|}{ Description } \\
\hline Feeding and watering practice & $\mathbf{N}$ & $\%$ \\
\hline \multicolumn{3}{|c|}{ Do you provide supplementary feed for your chicken } \\
\hline Yes & 30 & 100.0 \\
\hline No & - & - \\
\hline \multicolumn{3}{|c|}{ Why do you provide supplementary feed for your chicken } \\
\hline To increase egg yield & 21 & 70.0 \\
\hline To increase meat yield & 1 & 3.3 \\
\hline To shorting broodiness & 7 & 23.3 \\
\hline To increase egg yield and shorting broodiness & 1 & 3.3 \\
\hline Total & 30 & 100.0 \\
\hline \multicolumn{3}{|l|}{ Types if ingredients used as a supplementary feed } \\
\hline Wheat & 1 & 3.3 \\
\hline Barely & 2 & 6.7 \\
\hline Sorghum & 4 & 13.3 \\
\hline Maize & 21 & 70.0 \\
\hline Mixture & 2 & 6.7 \\
\hline Total & 30 & 100.0 \\
\hline \multicolumn{3}{|l|}{ How many times do you supply per day } \\
\hline Once & 1 & 3.3 \\
\hline Twice & 9 & 30.0 \\
\hline Three times & 20 & 66.7 \\
\hline Total & 30 & 100.0 \\
\hline \multicolumn{3}{|l|}{ How to supply the feed } \\
\hline In a feeding trough & 21 & 70.0 \\
\hline On a bare ground & 9 & 30.0 \\
\hline Other & - & - \\
\hline \multicolumn{3}{|l|}{ Do you provide water for your chicken } \\
\hline Yes & 30 & 100.0 \\
\hline No & - & - \\
\hline \multicolumn{3}{|l|}{ How many times per day } \\
\hline Once & 2 & 6.7 \\
\hline Twice & 6 & 20.0 \\
\hline Three times or more & 22 & 73.3 \\
\hline Total & 30 & 100.0 \\
\hline
\end{tabular}

Incubation and hatchery management of chicken

Based on the information obtained from the respondents, the entire households in the study area were hatching the egg by using natural incubation. According to the information obtained during the survey, all the selected households were use broody hens as a natural incubation. As illustrated in Table 7, most of the households were used Teff straw during hatching of the egg by natural incubation/broody hens (40\%). Based on the information obtained from the respondents, the overall incubation period of chicken in the study area was $21.82 \pm 0.14$ days. Similar to the current result, [9] reported that the overall incubation period of local chicken in Meket 
district was 21.7 days.

Table 7. Incubation and hatchery management of chicken in the study area.

\begin{tabular}{lll}
\hline Description & N & \% \\
\hline Incubation and hatchery management & & \\
\hline How do you hatching the egg & 30 & 100.0 \\
$\begin{array}{l}\text { By using natural incubation } \\
\text { By using artificial incubation }\end{array}$ & - & - \\
What types of chicken do you use as a natural incubation & & \\
Broody hens & 30 & 100.0 \\
Non broody hens & - & - \\
Others & - & - \\
Which types of materials do you use during natural & & \\
incubation & & \\
Clay pot and straw bedding & 3 & 10.0 \\
Clay pot only without bedding & 2 & 6.7 \\
Teff straw & 12 & 40.0 \\
Wheat straw & 7 & 23.3 \\
Barely straw & 6 & 20.0 \\
Total & 30 & 100.0 \\
The incubation period of chicken in the study area & Mean \pm SE \\
& $21.82 \pm 0.14$ \\
\hline
\end{tabular}

Productive performances of local chicken ecotype

The current study indicates, the average matured weight of local hen and cock in the study area was $1.23 \pm 017$ and $1.75 \pm 0.32 \mathrm{Kg}$, respectively. Whereas, the average matured weight of exotic hen and cock in the study area was $2.72 \pm$ 0.23 and $3.43 \pm 0.42$, respectively. As illustrated in Table 8, the current result was higher than the report of [14] who reported that the average weight of local hens and cocks found in north western Amhara region was $1.12 \pm 0.021$ and $1.4 \pm 0.31 \mathrm{Kg}$, Respectively. The current result was also higher that the report of [15] who reported that the average matured weight of local hen and cock found in Meket district was $1.13 \pm 0.17$ and $1.63 \pm 0.32$, respectively. This indicated that, there is enough grain availability and better management in Chiro town.
Table 8. Average weight of local hens and cocks under farmer's management condition ( $N=240$ Birds).

\begin{tabular}{lllll}
\hline \multirow{2}{*}{ Parameters } & \multicolumn{3}{l}{ Chicken Ecotype } \\
\cline { 2 - 5 } & \multicolumn{1}{l}{ Local } & \multicolumn{3}{l}{ Exotic } \\
\cline { 2 - 5 } & Mean \pm SD & Range & Mean \pm SD & Range \\
\hline $\begin{array}{l}\text { Average weight of } \\
\text { local hens (Kg) }\end{array}$ & $1.23 \pm 0.17$ & $0.5-2.1$ & $2.72 \pm 0.23$ & $1.25-3.51$ \\
$\begin{array}{l}\text { Average weight of } \\
\text { local cocks (Kg) }\end{array}$ & $1.75 \pm 0.32$ & $0.6-2.7$ & $3.43 \pm 0.42$ & $1.5-4.53$ \\
\hline
\end{tabular}

$\mathrm{N}=$ number of chicken used for body weight measurement, $\mathrm{SE}=$ Standard Error

\section{Reproductive performances of local chicken ecotype}

The average age at first mating of local and exotic cockerels in the study area was 6.9 months and 6.09 months, respectively. According to the information obtained from the respondents, the average age at first egg of local and exotic pullets was 7.4 month and 6.8 month. Similar studies by different authors also indicates that, the age at sexual maturity of female birds in Tanzania were 28 weeks [16], 24 weeks in Mali [17], 32 weeks in Sudan [18] 28 to 36 weeks in Benin [19]. The average number of egg laid /clutch and annual productivity of local hens in the study town were $12.3 \pm 0$. (Range 7 to 21 ) and $47.57 \pm 1.1$ (range 35 to 85 ) eggs, respectively, while, The average number of egg laid /clutch and annual productivity of exotic hens were $200 \pm 2.47$ (range 150-250) and 257.6 2 .1 (200-300). Similar to the current finding, [19] reported that the average number of eggs/clutch in northwest Ethiopia was ranges from 9 to 19 . The current result indicates that, exotic chicken was early matured and more productive than local chicken under similar management condition. This might be due to genetic factor and feed conversion efficiency.

Table 9. Performance of local and exotic hens under farmer's management condition.

\begin{tabular}{|c|c|c|c|c|}
\hline \multirow{3}{*}{ Parameters } & \multicolumn{4}{|c|}{ Chicken Ecotype } \\
\hline & \multicolumn{2}{|c|}{ Local } & \multicolumn{2}{|l|}{ Exotic } \\
\hline & Mean \pm SD & Range & Mean \pm SD & Range \\
\hline Egg laid/ clutch & $12.3 \pm 0.1$ & $7-21$ & $200 \pm 2.47$ & $150-250$ \\
\hline Average number of egg set & $11.4 \pm 0.8$ & $6-21$ & $20 \pm 1.42$ & $10-25$ \\
\hline Number of egg hatched & $8.9 \pm 0.2$ & $6-17$ & $15.57 \pm 1.57$ & $8-25$ \\
\hline Number of chick survived & $6.3 \pm 0.8$ & $1-12$ & $9.77 \pm 1.70$ & $4-23$ \\
\hline Survivability percentage & $60.7 \pm 1.2$ & $20-100$ & $65.10 \pm 1.26$ & $10-85$ \\
\hline Number of clutch period/year/hen & $2.2 \pm 0.1$ & $2-4$ & $1.2 \pm 0.09$ & $0-2$ \\
\hline Egg production year per hen & $47.57 \pm 1.1$ & $35-85$ & $257.6 \pm 2.1$ & $200-300$ \\
\hline Age at first mating of cockerels (in month) & $6.9 \pm 0.09$ & $5-6$ & $6.09 \pm 0.05$ & $5-7$ \\
\hline Age at first egg of pullets (in month) & $7.4 \pm 0.07$ & $5-9$ & $6.8 \pm 0.2$ & $5-7$ \\
\hline
\end{tabular}

$\mathrm{SD}=$ standard deviation, $\mathrm{N}=$ Number of Households

\section{Marketing systems}

Based on the information obtained from the respondents, most of the households in the study area were sold their chicken through formal market $(73.3 \%)$ for the consumers $(86.7 \%)$. As summarized in Table 10 , mostly women's were responsible for chicken marketing in the study area $(86.7 \%)$. According to the information obtained during the survey, most of the households in the study area were transport their chicken to the market place by hanging by hand (93.3\%). Based on the information obtained from the respondents, the major constraints of chicken marketing in the study area were instable chicken price, poor sales/demand seasonality, poor infrastructure, lack of credit/financial support and lack of market place. 
Table 10. Chicken marketing systems in the study area.

\begin{tabular}{lll}
\hline Description & N & \% \\
\hline Chicken marketing systems & & \\
\hline How do you sell your chicken and chicken products & & 73.3 \\
Through formal market & 22 & 20.0 \\
Through informal market & 6 & 6.3 \\
Both & 2 & 100.0 \\
Total & 30 & \\
How are responsible for chicken marketing & & 13.3 \\
Man & 4 & 86.7 \\
Women & 26 & - \\
Children & - & 100.0 \\
Total & 30 & \\
How to transport your chicken to the market place & & - \\
By pack animals & - & 93.3 \\
Hanging by hand & 28 & 6.7 \\
Hanging with stick & 3 & 100.0 \\
Total & 30 & \\
To whom you sell your chicken & & 86.7 \\
For consumers & 26 & 10.0 \\
For retailers & 3 & 3.3 \\
For intimidators & 1 & 100.0 \\
Total & 30 & \\
\hline
\end{tabular}

\section{Major constraints of chicken production and marketing}

Based on the information collected from the respondents during the study period, lack of demand during fasting period, seasonal diseases outbreak and impact of predator was the major constraints of chicken production in Chiro town with an index of $0.24,0.19$ and 0.18 , respectively. Based on the information collected from group discussion, religious/culture/holiday was highly associated with production, marketing and consumption of chicken products. Orthodox Christian fasting period were highly related with decreased consumption/demand of chicken and egg fluctuation/seasonality in price of chicken and egg products was the major chicken and egg marketing constraints. The other marketing constraint collected from the respondents, in the study area include presence of limited market outlets, lack of appropriate chicken and egg marketing information, lack of chicken transportation and egg handling facilities, lack of credit and capital to expand chicken production (Table 11).

Table 11. Major constraints of chicken production in the study area.

\begin{tabular}{lllll}
\hline & \multicolumn{5}{l}{ Study area (Chiro town) } \\
\cline { 2 - 5 } Major constraints of chicken production & \multicolumn{3}{l}{ Rank } & \\
\cline { 2 - 5 } & $\mathbf{1}^{\text {st }}$ & $\mathbf{2}^{\text {nd }}$ & $\mathbf{3}^{\text {rd }}$ & Index \\
\hline Low supply of marketable chicken products & 2 & 2 & 3 & 0.08 \\
Predation/impact of predator & 4 & 5 & 6 & 0.18 \\
Lack of capital and credit & 4 & 8 & 3 & 0.17 \\
Lack of demand during fasting period & 10 & 3 & 7 & 0.24 \\
Seasonal disease outbreak & 5 & 7 & 4 & 0.19 \\
Drought & 0 & 0 & 0 & 0.00 \\
Lack of credit and capital & 1 & 1 & 1 & 0.04 \\
Labor & 1 & 1 & 3 & 0.05 \\
Lack of veterinary service & 3 & 2 & 2 & 0.06 \\
\hline
\end{tabular}

Index $=$ sum of [ 3 for rank $1+2$ for rank $2+1$ for rank 3$]$ for particular constraints divided by sum of [ 3 for rank $1+2$ for rank $2+1$ for rank 3 ] for all constraints.

\section{Common chicken diseases}

The current study revealed that, the most common chicken diseases in the study area were New castle diseases, Avian influenza and Fowl pox, which are ranked first, second and third with an index of $0.24,0.18$ and 0.17 . According to the information obtained during group discussion during the study period, mortality of village bird due to diseases outbreak was usually higher during the start of rainy season, especially April and May. Similar to the current results, New castle disease was the major infectious diseases affecting productivity and survival of village chicken in northwestern Amhara [14]. New castle diseases was the major infectious diseases affecting productivity and survival of village chicken in the central highland of Ethiopia [20].

Table 12. Common diseases of chicken in the study area.

\begin{tabular}{lllll}
\hline Chicken diseases & \multicolumn{4}{l}{ Study area (Chiro town) } \\
\hline \multirow{2}{*}{ Common name } & Rank & $\mathbf{3}^{\text {rd }}$ & Index \\
\cline { 2 - 5 } & $\mathbf{1}^{\text {st }}$ & $\mathbf{2}^{\text {nd }}$ & 4 & 0.24 \\
\hline New castle diseases & 7 & 9 & 6 & 0.18 \\
Avian influenza & 5 & 4 & 6 & 0.17 \\
fowl pox & 6 & 5 & 5 & 0.08 \\
Air sac disease & 1 & 4 & 2 & 0.10 \\
Mushy chick & 4 & 2 & 1 & 0.11 \\
Fowl cholera & 5 & 2 & 4 & 0.06 \\
Botulism & 1 & 2 & 2 & 0.05 \\
Bumble foot & 1 & 2 & 6 \\
\hline
\end{tabular}

Index $=$ sum of $(3$ for rank $1+2$ for rank $2+1$ for rank 3$)$ give for each disease divided by sum of ( 3 for rank $1+2$ for rank $2+1$ for rank 3 ) for all disease.

\section{Risk Aversion Strategies}

The result of this study indicates that, $71.7 \%$ of chicken owners reared birds mainly during dry season, when the risk of disease outbreak and predation is low. Only $20.3 \%$ of village chicken owners reared birds throughout the year. It is identified that $77.2 \%$ of those chicken owners who reared chicken throughout the year used various risk aversion strategies throughout the year. Accordingly, reduction of flock size and keeping only some productive birds (84.6\%) was the most preferred strategies implemented by chicken owners. Similar to the current finding, [14] reported that $69.3 \%$ of chicken owners in north western Amhara region reared birds mainly during dry season, when the risk of disease outbreak and predation is low and reduction of flock size and keeping only some productive birds (84.6\%) was the most preferred strategies implemented by chicken owners.

\section{Conclusion and Future Scope}

Poultry production is one of income generation system and widely practiced by farmers in study area. It is practiced by every farmers as side line with other farming activities and offer farmers with further income. It also used as starting point for young to establish business idea. The result the current study indicated that local chicken ecotype were dominant for the existing production system. As observed in 
this study chicken production in study area was hindered due to poor management like health care, feed shortage, lack of improved breed and predators. This shows there is a need to intervene to reduce chicken mortality and improve productivity. So, this problem can be overcome by slight advance in poultry house, cross breeding with exotic breeds and vaccination of chicken. Therefore, information should be disseminate to farmers about chicken husbandry and government should provide vaccine and improved breeds of chicken for farmers.

\section{Acknowledgements}

We would like to express our sincere appreciation to Chiro Town Administration office and Livestock Development, Health and Marketing Agency and all staff members for providing the necessary baseline data for this study. We would like to appreciate and acknowledge the households who participated on the interview. We would also like to acknowledge the Development Agents in the study Peasant Associations for their critical support in data collection.

\section{References}

[1] T. Dessie. "Phenotypic and genetic characterization of local chicken ecotypes in Ethiopia", PhD Thesis, Humboldt University of Berlin, Germany, pp: 209, 2003.

[2] T. Dessie, "Studies on village poultry production systems in the central highlands of Ethiopia", MSc thesis. Swedish University of Agricultural Sciences, 70 pp, 1996.

[3] A. Melesse, "Comparative studies on performance and physiological responses of Ethiopian indigenous ('Angetemelata') chicken and their F1 crosses to long term heat stress:, $\mathrm{PhD}$ thesis. Martin-Luther University, Halle-Wittenberg, Berlin, Germany. Pp. 182, 2000.

[4] A. Melese, S. Gizaw, "Study on Characterization of Local Chickens in Southern Ethiopia Proceeding Held in Hawassa.

[5] CSA (Central Statistical Agency of the Federal Democratic Republic of Ethiopia), "Agricultural Sample Survey of Volume II, Report on Livestock and Livestock Characteristics (Private Peasant Holdings), Central Statistical Agency, Addis Ababa, Ethiopia, 2016/17 (2009 E. C)”.

[6] T. N. Gondwe, C. B. Wollny, W. Kaumbata, "Marketing system and channels for scavenging local chickens in Lilongwe, Malawi”, Livestock Research for Rural Development. Vol. 17, pp. 1-24, 2005.

[7] H. Aklilu., C. J. M. Almekinders, V. D. Zijpp, "Village poultry consumption and marketing in relation to gender, religious festivals and market access", Tropical Animal Health and Production 39, 165-168, 2007.
[8] SPSS Version. 20.0. 2013. Software Package for Social Sciences for Window.

[9] T. d. Assefa, M. A. Ewubetu, "Characterization of village Chicken production systems and marketing practice in Meket district, North Wollo Zone, Ethiopia", Internation journal of Scientific research in chemical science, Vol. 7, Issue. 1, pp. 16, 2020.

[10] D. Tadelle, T. Million, Y. Alemu, KJ Peters, "Village chicken production systems in Ethiopia: Use patterns and performance valuation and chicken products and socio-economic functions of chicken", Livestock Research for Rural Development (15) 1, 2003a.

[11] S. Gizaw., A, Tegegne, B. Gebremedhin, D Hoekstra, "Sheep and goat production and marketing systems in Ethiopia: Characteristics and strategies for improvement. IPMS (Improving Productivity and Market Success) of Ethiopian Farmers Project Working Paper 23. ILRI", (International Livestock Research Institute), Nairobi, Kenya. 58p.

[12] E. B. Sonaiya, S. J. Swan, "Small-scale poultry production, technical guide manual", FAO Animal Production and Health 1. FAO (Food and Agriculture Organization of the United Nations), Rome, Italy, 2004.

[13] C. Mapiye, S. Sibanda, "Constraints and opportunities of village chicken production systems in the smallholder sector of Rushinga District of Zimbabwe", Livestock Res Rural Development, 2005.

[14] F. Moges, M. Nega, G. Zeleke, "Characterization of Village chicken production and marketing system in North Amhara region, Ethiopia", African journal of agricultural research, Vol. 9 (14), 2014.

[15] S. Salo, G. Tadesse, D, Hilemeskel, "Village Chicken Production System and Constraints in Lemo District, Hadiya Zone, Ethiopia”, Poult Fish Wildl Sci 4: 158., 2016.

[16] A. M. Katule "Study on potential value of indigenous chickens in Tanzania”, rural. Poult. Dev. Newsl, pp, 1-4, 1992.

[17] A. I. Kassambara, "La production Avicole AU Mali: problems et perspectives. In: proceeding of international workshop on rural poultry in Africa", lle-lfe, Nigeria, pp, 140-150, 1989.

[18] R. T. Wilson, A. Traore, H. G. Kuit, M. Slingerland, "Livestock production in central Mali: Reproduction, growth and mortality of domestic fowl under traditional management". Tropical Animal Health and Production 19 (4): 229-236, 1987.

[19] H. H. Mogesse, "Phenotypic and genetic characterization of indigenous chicken populations in northwest Ethiopia. $\mathrm{PhD}$ thesis. Faculty of Natural and Agricultural Sciences, Department of Animal, Wildlife and Grassland Sciences, University of the Free State, Bloemfontein, South Africa.

[20] S. Tadesse, H. Ashenafi, Z. Aschalew, "Sero-prevalence study of Newcastle disease in local chickens in central Ethiopia", International Journal of Applied Research Vet. Med. 3 (1): 25 29, 2005. 